\title{
LA CONSTITUCIÓN MEXICANA DE 1917 Y LAS FACULTA- DES EN MATERIA DE COMERCIO EXTERIOR
}

\author{
THE MEXICAN CONSTITUTION OF 1917 AND THE FACULTIES ON FOR- \\ EIGN TRADE \\ OSCAR CRUZ BARNEY ${ }^{1}$
}

Resumen: La política exterior de México ha evolucionado a través del tiempo como consecuencia directa de la globalización y el comercio internacional que esta introdujo. En este ensayo se hace un breve recorrido histórico por las medidas y políticas mercantiles que se han implementado en nuestra nación desde 1778 hasta la actualidad con el propósito de regular, promover y desarrollar el comercio exterior y fortalecer el papel que México desempeña dentro del mismo.

Palabras clave: Tratados internacionales, comercio exterior, politica mercantil, relaciones comerciales, mercado global.

Aвstract: The foreign policy of Mexico has evolved through time as a direct result of globalization and the international trade it introduced. In this essay we make a brief historic recount through the measures and mercantile policies that have been implemented in our nation since 1778 to the present with the purpose of regulating, promoting and developing foreign trade as well as strengthening the role that Mexico plays within it.

Keywords: International treaties, foreign trade, commercial policy, commercial relations, global market.

SumARIO: I. Introducción; II. Evolución de las relaciones comerciales internacionales de México; III. La regulación del comercio exterior en el siglo XIX; IV. El México independiente; V. La Constitución Federal de 1857; VI. La Constitución de 1917; VII. Consideración final; VIII. Fuentes.

${ }^{1}$ Investigador del Instituto de Investigaciones Jurídicas de la UNAM. Doctor en Derecho con Mención Honorífica por la Universidad Panamericana y licenciado en derecho con Mención Honorífica por la Universidad Iberoamericana. Título de Licenciado en Derecho homologado a Título universitario oficial español de Licenciado en Derecho por el Ministerio de Educación, Cultura y Deporte de España.<ocbarney@unam.mx>. ORCID: https://orcid.org/0000-0001-7927-1564 Fecha de recepción: 17 de mayo de 2019; fecha de aprobación: 30 de septiembre de 2019 . 


\section{INTRODUCCIÓN}

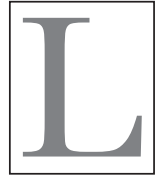

a Constitución Política de los Estados Unidos Mexicanos se refiere en diversos artículos al tema del comercio internacional y a las facultades que para su regulación, promoción y desarrollo ostentan tanto el Ejecutivo Federal como el Congreso de la Unión o el Senado de la República. La facultad originaria para regular el comercio exterior de México se encuentra en la fracción XXIX del Artículo 73 constitucional. En ella se establece que es facultad del Congreso legislar para establecer contribuciones sobre el comercio exterior.

Por su parte, el Artículo 131 es uno de los dos casos, junto con el Artículo 29 en la Constitución en las que se rompe el principio de división de poderes consagrado en el Artículo 49 constitucional. ${ }^{2}$ Dicho Artículo establece: "El Supremo Poder de la Federación se divide para su ejercicio en Legislativo, Ejecutivo y Judicial. No podrán reunirse dos o más de estos Poderes en una sola persona o corporación, ni depositarse el Legislativo en un individuo, salvo el caso de facultades extraordinarias al Ejecutivo de la Unión, conforme a lo dispuesto en el artículo 29. En ningún otro caso, salvo lo dispuesto en el segundo párrafo del artículo 131, se otorgarán facultades extraordinarias para legislar."

El Artículo 131 constitucional regula la facultad para imponer aranceles al comercio exterior. Se establece en su redacción vigente:

Artículo 131. Es facultad privativa de la Federación gravar las mercancías que se importen o exporten, o que pasen de tránsito por el territorio nacional, asi como reglamentar en todo tiempo y aún prohibir, por motivos de seguridad o de policía, la circulación en el interior de la República de toda clase de efectos, cualquiera que sea su procedencia.

${ }^{2}$ Véase Cruz Barney, Oscar, “Artículo 131”, en Arriola, Juan Federico (Coord.), Constitución Política Mexicana en su Centenario, México, Editorial Trillas, 2017, págs. 852 y sigs. 
El Ejecutivo podrá ser facultado por el Congreso de la Unión para aumentar, disminuir o suprimir las cuotas de las tarifas de exportación e importación, expedidas por el propio Congreso, y para crear otras; asi como para restringir y para prohibir las importaciones, las exportaciones y el tránsito de productos, articulos y efectos, cuando lo estime urgente, a fin de regular el comercio exterior, la economía del pais, la estabilidad de la producción nacional, o de realizar cualquiera otro propósito, en beneficio del pais. El propio Ejecutivo al enviar al Congreso el Presupuesto Fiscal de cada año, someterá a su aprobación el uso que hubiese hecho de la facultad concedida.

Esta redacción, como veremos, es producto de la evolución que ha experimentado nuestro país en sus relaciones comerciales internacionales, en su política arancelaria y aduanera. Si bien es un artículo que ha sufrido muy pocas reformas desde su redacción original en 1917.

\section{Evolución de las relaciones comerciales internacio- NALes de MÉxico}

En 1778 se adopta en el mundo hispanoamericano el sistema del comercio libre mediante el Reglamento y aranceles reales para el comercio libre de España y las Indias del 12 de octubre de ese año ${ }^{3}$ y la Pragmática de libertad de comercio de misma fecha. Se pensaba que el cambio de sistema serviría para mejorar el aprovechamiento del comercio con los reinos americanos, con el abandono del antiguo sistema de flotas y galeones. El Reglamento de 1778 "condensa y simboliza el espíritu reformista en el campo de la economía."

El cambio consistía en habilitar más puertos españoles para el comercio con América, los puertos habilitados eran desde 1765:

${ }^{3}$ Reglamento y aranceles reales para el comercio libre de España y las Indias de 12 de octubre de 1778, Madrid, Imprenta de Pedro Marín, 1778.

${ }^{4}$ Langue, Frédérique, "Hombres e ideas de la ilustración en dos ciudades consulares: Caracas y Veracruz", Historia Mexicana, México, El Colegio de México, núm. 179, enero-marzo, 1996, pág. 469. 
Cádiz, Santander, Gijón, La Coruña, Sevilla, Málaga, Cartagena. Alicante y Barcelona, ${ }^{5}$ sumándose con el Reglamento los de Alfaques de Tortosa, Santa Cruz de Tenerife y Palma de Mallorca en España. Los puertos americanos para el comercio directo en 1765 fueron Santiago de Cuba, Santo Domingo, Puerto Rico, Margarita y Trinidad. ${ }^{6}$ Con el Reglamento de 1778 se añadieron Monte Christi en la Isla Española, Batabanó, y La Habana; Campeche, el Golfo de Santo Tomás de Castilla, y el Puerto de Omoa en el Reino de Guatemala; Cartagena, Santa Marta, Rió de la Hacha, Portobelo, Chagre en el de Santa Fe, y Tierra Firme; (exceptuando los de Venezuela, Cumaná, Guayana y Maracaibo concedidos a la Compañía de Caracas sin privilegio exclusivo), Montevideo y Buenos-Ayres en el Río de la Plata; Valparaíso, y la Concepción en el Reino de Chile; y los de Arica, Callao, y Guayaquil en el Reino del Perú y costas de la Mar del Sur. ${ }^{7}$ Se crea así, un área para el intercambio comercial sujeta a una regulación jurídica uniforme, con especial atención al intercambio recíproco dentro del área indiana.

Anteriormente se había instaurado el sistema de avisos en 1764, que consistía en un sistema regular de correos entre España e Indias, autorizados para el transporte de mercaderías, sucesivamente se fueron adoptando diversas medidas liberalizadoras del comercio

${ }^{5}$ Real Decreto en que S.M. ha resuelto ampliar la concesión del comercio libre, contenida en Decreto de 16 de octubre de 1765 . Instrucción de la misma fecha, y demás resolciones posteriores, que solo comprehendieron las Islas de Barlovento, y provincias de Campeche, Santa Marta, y Rio del Hacha, incluyendo ahora la de Buenos-Ayres, con internacion por ella à las demás de la America Meridional, y extension à los Puertos Habilitados en las Costas de Chile, y el Perú, $\Xi^{2}$. Expedido en 2 de febrero de 1778, Madrid, por Juan de San Martin, Impresor de la Secretaría de Estado y del Despacho Universal de Indias, 1778, AGN, Bandos, vol.10, exp. 42, fs. 308-311.

${ }^{6}$ Montenegro Duque, Angel, Historia de España, Madrid, ed. Gredos, tomo 10, 1991, pág. 267.

${ }^{7}$ Reglamento de 1778 , arts. 4 y 5. 
que fueron reunidas en el mencionado Reglamento de $1778 .{ }^{8}$

Del antiguo sistema se mantuvo la exigencia de que fueran españoles los titulares del tráfico comercial y española o naturalizada española las dos terceras partes de la tripulación, lo que se debía hacer constar ante los jueces de Indias en los respectivos puertos habilitados. ${ }^{9}$ Además, se buscó fomentar la construcción de embarcaciones para el comercio atlántico ${ }^{10}$, haciendo una rebaja de una tercera parte de los derechos adeudados en el primer viaje a las Indias por los frutos embarcados de cuenta propia a quien fabricare navío mercante de trescientas toneladas o más. ${ }^{11}$ El Reglamento de 1778 concedió la exención del pago de los derechos de palmeo, tonelada, San Telmo, extranjería, visitas, reconocimientos de carenas, habilitaciones, licencias para navegar y demás gastos y formalidades establecidos en el Proyecto de 1720 mismo que quedó revocado para toda la nueva zona de libertad comercial, reservándose formar el correspondiente para el comercio y negociación con la Nueva España y permitir que a partir de 1779 los navíos de registro anual de azogues llevaren a Veracruz los frutos y manufacturas de España. ${ }^{12}$ Una de las innovaciones del Reglamento fue la introducción de dos aranceles, uno para los géneros registrados para las Indias y otro para los enviados a España.

${ }^{8}$ Gortari Palacios, Hira de, "El comercio novohispano a través de Veracruz", Historia Mexicana, México, El Colegio de México, núm. 67, enero-marzo, 1968, pág 430 .

${ }^{9}$ Reglamento de 1778 , arts. 1 y 3 . El tercio restante podía integrarse de extranjeros católicos.

${ }^{10}$ Sobre el tema de la nacionalización de la flota mercante española ver Alfonso Mola, Marina, "La Marina Mercante colonial en la legislación borbónica (17001828)", en Martínez Shaw, Carlos (Ed.), El derecho y el mar en la España moderna, Granada, Universidad de Granada, Centre d'estudis d'historia moderna Pierre Vilar, 1995.

${ }^{11}$ Reglamento de 1778 , arts. 3 y 33.

12 Ibidem, art. 6. 
La posterior declaración de guerra con la Gran Bretaña retrasó la expansión del Comercio Libre a los puertos habilitados y la incorporación de la Nueva España en el nuevo régimen comercial. De hecho, la reglamentación para la libertad de comercio con el virreinato novohispano nunca llegó a elaborarse. ${ }^{13}$ No fue sino hasta la expedición del Real Decreto de 28 de febrero de 1789, más otro de 10 de julio $^{14}$, que se amplió la libertad comercial a Nueva España y Caracas. ${ }^{15}$

En 1779 se liberalizó el tráfico negrero y en 1797 mediante Real Orden de 18 de noviembre se autorizó a los americanos el llamado comercio neutral. ${ }^{16}$

III. LA REgulación DEL COMERCIO EXTERIOR EN EL SIGLO XIX

Diversas disposiciones que afectaron al comercio exterior se dictaron por las Cortes entre 1811 y $1815 .{ }^{17}$ El 23 de marzo de 1811 las Cortes generales y extraordinarias decretaron la extensión a las In-

${ }^{13}$ Ortiz de la Tabla Ducasse, Javier, Comercio exterior de Veracruz 1778-1821 crisis de dependencia, Sevilla, Escuela de Estudios Hispanoamericanos de Sevilla, G.S.I.C., 1978, págs. 7-8.

${ }^{14}$ Muro, Luis, "Revillagigedo y el comercio libre (1791-1792)", Extremos de México. Homenaje a don Daniel Cosío Villegas, México, El Colegio de México, 1971, pág 299.

${ }^{15}$ Real Decreto de 18 de Febrero de 1789, en Pérez y López, Antonio Xavier, Teatro de la Legislación Universal de España e Indias, Madrid, en la Oficina de Don Gerónimo Ortega y Herederos de Ibarra, 1794, t.VII.

${ }^{16}$ Véase Souto Mantecón Matilde, "El Consulado de Veracruz ante el comercio extranjero: 1799-1819”, en Meyer Cosío, Rosa María (coord.), Identidad y prácticas de los grupos de poder en México, siglos XVII-XIX, México, Instituto Nacional de Antropología e Historia, 1999, colección científica, serie historia, pág125. Sobre el tema a Muñoz Pérez, José "El comercio de Indias bajo los Austrias y los tratadistas españoles del siglo XVII", Revista de Indias, núm. 68, año XVII, abril-junio, 1957.

17 Sobre el tema véase Cruz Barney, Oscar, El comercio exterior de México, 18211928, México, Instituto de Investigaciones Jurídicas, UNAM, 2005. 
dias de la libertad de derechos de alcabalas y cientos en la venta de embarcaciones españolas y extranjeras. ${ }^{18}$ En enero de 1812 se extinguieron las matrículas de mar para las provincias americanas. ${ }^{19}$

El 20 de octubre de 1820 se expidió un Arancel General de Aduanas ${ }^{20}$ para toda la Monarquía que empezó a regir en Europa el 1 de enero de 1821 y en América treinta días después de que arribase la orden y el arancel a las provincias de ultramar. Se debía cobrar un solo derecho por cuenta de la Hacienda pública en la entrada y salida de los géneros del comercio extranjero. El artículo 26 del arancel ordenó el establecimiento de depósitos para el comercio marítimo.

Las Cortes de España expidieron, en cumplimiento del artículo 26 citado, el Decreto de 9 de noviembre de 1820 sobre Establecimiento de Depósitos ${ }^{21}$ que habilitaba varios puertos de México al comercio lícito directo con España. Específicamente se trataba de los puertos de Acapulco, San Blas, Campeche, Veracruz y Tampico. Se estableció

${ }^{18}$ Véase Orden Por la que se manda estender á las Américas la libertad de derechos de alcabalas y cientos en la venta de embarcaciones españolas y estranjeras, en Colección de los Decretos y órdenes que han espedido las Cortes generales y estraordinarias, desde su instalación, de 24 de setiembre de 1810 hasta (11 de mayo de 1814 en que fueron disueltas) Mandada publicar de órden de las mismas. Cuarta parte del Semanario Judicial,Imprenta de J.M. Lara, México, 1852-1853, Tomo I, pág. 79.

${ }^{19}$ Véase Decreto CXIX de 14 de enero de 1812. Estincion de las matriculas de mar en las provincias ultramarinas, en Colección de los Decretos y órdenes que han espedido las Cortes generales y estraordinarias, desde su instalación, de 24 de setiembre de 1810 hasta (11 de mayo de 1814 en que fueron disueltas) Mandada publicar de órden de las mismas. Cuarta parte del Semanario Judicial,Imprenta de J.M. Lara, México, 1852-1853, Tomo I, pág. 199.

${ }^{20}$ Arancel General de Aduanas de 5 de octubre de 1820, en Colección de los decretos y órdenes generales de la primera legislatura de las Cortes ordinarias de 1820 y 1821, desde 6 de julio hasta 9 de noviembre de 1820. Mandada publicar de orden de las mismas, Madrid, Imprenta Nacional, 1821, Tomo VI, págs.170-178.

${ }^{21}$ Decreto de 9 de noviembre de 1820 sobre Establecimiento de Depósitos, en Colección de los decretos y órdenes generales de la primera legislatura de las Cortes ordinarias de $1820 y$ 1821, desde 6 de julio hasta 9 de noviembre de 1820. Mandada publicar de orden de las mismas, Madrid, Imprenta Nacional, 1821, Tomo VI, págs.383-384. 
que se habilitarían los puertos de Tehuantepec, Mazatlán de los Mulatos, San Diego de las Californias, Tlacotalpan, Tamiagua y Soto de la Marina.

En el citado decreto de 9 de noviembre se declaró abolido y sin ningún efecto el Reglamento de Comercio Libre de 12 de octubre de 1778 al considerarlo incompatible con el régimen constitucional, con la reforma a la Ordenanza de Matrículas de Mar y con el Arancel General de Aduanas de 5 de octubre de 1820.

En esa misma fecha se expidió el Decreto sobre comercio libre con las islas Filipinas. ${ }^{22}$ Conforme al citado decreto, todos los géneros y manufacturas filipinas ${ }^{23}$ se admitirían en los puertos españoles habilitados tanto de América como de Europa y Asia como productos nacionales. Se autorizaba asimismo que todo buque nacional hiciese el comercio directo desde cualquier puerto español de América y de Europa a los puertos extranjeros de la India oriental y de China, pudiendo a su vez introducir en los puertos americanos o europeos habilitados los siguientes productos: Canela de Ceilán, perlas, diamantes, marfil, carey, té de todas clases, loza de China, muebles de madera charolados, concha, nácar manufacturada, marfil manufacturado, carey manufacturado, filigrana de todas clases, tintas, cajitas de pinturas, abanicos de marfil, de talco y cola de pescado, azúcar en piedra o cande y otras manifacturas de algodón, seda y hierbas.

${ }^{22}$ Decreto sobre comercio libre con las islas Filipinas, en Colección de los decretos y órdenes generales de la primera legislatura de las Cortes ordinarias de 1820 y 1821, desde 6 de julio hasta 9 de noviembre de 1820. Mandada publicar de orden de las mismas, Madrid, Imprenta Nacional, 1821, Tomo VI, págs.378-380.

${ }^{23}$ Sobre el impacto de las reformas borbónicas en el comercio con Filipinas véase Alonso Alvarez, Luís, "El impacto de las reformas borbónicas en las redes comerciales. Una visión desde el Pacífico hispano, 1762-1815”, en Antonio Ibarra y Guillermina del Valle Pavón, Redes sociales e instituciones comerciales en el imperio español, siglos XVII a XIX, México, Instituto Mora, Facultad de Economía, UNAM, 2007. 
$\mathrm{Al}$ nacer a la vida independiente, el país carecía de un sistema arancelario adecuado a su nueva realidad política y económica: pasó de un sistema controlado de comercio, si bien liberalizado en la última mitad del siglo XVIII, pero siempre bajo el control de grupos de comerciantes a través de los Consulados de Comercio y con la presencia clara del Estado Español en la regulación de las transacciones entre España y las Indias.

En ese sentido, para entender la política arancelaria mexicana es necesario acudir a sus antecedentes hispano-indianos para después estudiar la regulación específica que prevaleció durante el siglo XIX.

Conforme a la Constitución de Cádiz de 1812, no podía el Rey hacer alianza ofensiva, ni tratado especial de comercio con ninguna potencia extranjera sin el consentimiento de las Cortes.

\section{iv. El México independiente}

Alcanzada la independencia en $1821^{24}$, conforme al proyecto del Reglamento Político Provisional del Imperio Mexicano de 1822 correspondía al Emperador dirigir las relaciones diplomáticas y de comercio con las demás naciones. La Soberana Junta Provisional Gubernativa aprobó 15 de diciembre de 1821 lo que sería el primer arancel del México independiente, titulado Arancel general interino para gobierno de las aduanas maritimas en el comercio libre del Imperio. ${ }^{25}$ El Arancel era seguido de una Instrucción para el gobierno de las aduanas en el despacho

${ }^{24}$ En general para este periodo en adelante véase Cruz Barney, Oscar, El comercio exterior de México, 1821-1928, México, Instituto de Investigaciones Jurídicas, UNAM, 2005.

${ }^{25}$ Véase Arancel general interino para gobierno de las aduanas marítimas en el comercio libre del Imperio, en Dublán, Manuel y Lozano, José María, Legislación Mexicana ó colección completa de las disposiciones legislativas expedidas desde la independencia de la República, México, Imprenta del Comercio a cargo de Dublán y Lozano, Hijos, 1876, tomo I, núm. 260. 
de los barcos que han de cargar en los puertos del Imperio, oro, plata, frutos, géneros y efectos de exportación. El Arancel sancionaba en su artículo 1 la apertura de nuevos puertos al comercio exterior, de conformidad al decreto expedido por las Cortes de España ya señalado.

Existía la idea de impulsar la actividad mercantil en los puertos como una vía para enriquecimiento del Estado ${ }^{26}$, si bien en la práctica, según sostiene Ibarra Bellón, “...el gobierno central estuvo lejos de controlar las rentas originadas en el comercio exterior: su efectividad se vio minada por la desorganización que provocaban las constantes guerras, los levantamientos, la imposibilidad de dominar el extenso territorio, la ausencia de personal adecuado, los ataques indígenas, los constantes cambios en la legislación fiscal y la fuerza de los grupos regionales." 27

Adoptada la República Federal en 1824, correspondía al Congreso Arreglar el comercio con las naciones extranjeras, y entre los diferentes Estados de la Federación y tribus de los indios y al Presidente de la República dirigir las negociaciones diplomáticas, y celebrar tratados de comercio.

Con la República Central, dentro de la Tercera Ley Constitucional en 1836 el Congreso tenía facultad para dar al gobierno bases y reglas generales para la habilitación de toda clase de puertos, establecimiento de aduanas y formación de los aranceles de comercio. Esta facultad de mantiene en las Bases Orgánicas de 1843.

${ }^{26}$ Muñoz, Laura, "Los puertos mexicanos del Golfo durante los primeros años del México independiente: fuentes para su estudio", en América Latina en la Historia Económica. Boletín de Fuentes, México, Instituto de Investigaciones Dr. José María Luis Mora, Enero-Junio, Número 21, 2004, págs. 61-62.

${ }^{27}$ Ibarra Bellón, Araceli, El comercio y el poder en México, 1821-1864. La lucha por las fuentes financieras entre el Estado central y las regiones, México, Fondo de Cultura Económica, Universidad de Guadalajara, 1998, págs. 60-61. 
V. La CONSTITUCión FEdERAL DE 1857

La primera Ordenanza de aduanas se expidió en 1856. Se trata de la Ordenanza general de aduanas marítimas y fronterizas de la República Mexicana de 1856. Esta Ordenanza fue precedida por el Reglamento de Aduanas Maritimas, Fronterizas y de Cabotage de 1849. A la Ordenanza de 1856 le siguieron la Ordenanza general de aduanas marítimas y fronterizas de 24 de enero de 1885, la Ordenanza general de aduanas marítimas y fronterizas de 1 de marzo de 1887, y la Ordenanza general de aduanas maritimas y fronterizas de los Estados Unidos Mexicanos de 12 de junio de 1891 con sus reformas de principios del siglo XX.

De la Ordenanza de 1891 se preparó en 1899 una nueva edición en la que se refundieron todas las disposiciones posteriores y que se encontraban vigentes al 19 de abril de ese año.

El Artículo 72 de la Constitución Federal de 1857 facultaba al Congreso a Para expedir aranceles sobre el comercio extranjero, y para impedir, por medio de bases generales, que en el comercio de Estado a Estado se establezcan restricciones onerosas.

Las importaciones mexicanas se caracterizaron por ser fundamentalmente de bienes de consumo elaborados y en menor medida de bienes de producción, situación que se mantiene a lo largo de todo el siglo. Los textiles serán durante la primera mitad del siglo los principales productos de importación, mientras que los metales, minerales y tinturas vegetales serán los principales bienes exportados, además de productos agrícolas, pecuarios y fibras vegetales, estructura que se mantiene cuando menos hasta $1875 .{ }^{28}$

El Artículo 124 establecía que para el día 1 de junio de 1858 quedarían abolidas las alcabalas y aduanas interiores en toda la República. Este Artículo fue reformado el 22 de noviembre de 1886 en

${ }^{28}$ Herrera Canales, Inés, El comercio exterior de México 1821-1875, México, El Colegio de México, 1977, págs. 25 y 58. 
el sentido de que los Estados no podrían imponer ningún derecho por el simple tránsito de mercancías en la circulación interior. Sólo el Gobierno de la Unión podría decretar derechos de tránsito, pero únicamente respecto de efectos extranjeros que atraviesen el país por líneas internacionales e interoceánicas, sin estar en el territorio más tiempo que el necesario para la travesía y salida al extranjero.

Los Estados no prohibirían directa ni indirectamente la entrada a su territorio ni la salida de él, de ninguna mercancía, a no ser por motivo de policía; ni gravarían los artículos de producción nacional por su salida para el extranjero o por otro Estado.

Las exenciones de derechos que concedieran serían generales, no pudiendo decretarlas en favor de los productos de determinada procedencia. Asimismo, la cuota del impuesto para determinada mercancía sería una misma, sea cual fuere su procedencia, sin que pueda asignársele mayor gravamen que el que reportan los frutos similares de la entidad política en que se decrete el impuesto.

La mercancía nacional no podía ser sometida a determinada ruta ni a inspección o registro en los caminos, ni exigirse documento fiscal alguno para su circulación interior. Los Estados no podrían gravar la mercancía extranjera con mayor cuota que aquella cuyo cobro les haya sido consentido por ley federal.

Una nueva reforma a este Artículo 124 se hizo el 1o de mayo de 1896 para quedar:

"Es facultad privativa de la Federación gravar las mercancías que se exporten o importen, o que pasen de tránsito por el territorio nacional, así como reglamentar en todo tiempo y aun prohibir por motivos de seguridad o de policía, la circulación en el interior de la República de toda clase de efectos, cualquiera que sea su procedencia; pero sin que la misma Federación pueda establecer ni dictar en el Distrito y Territorios federales, los impuestos y leyes que expresan las fracciones VI y VII del artículo $111 . "$ 
Será el antecedente directo de la redacción del Artículo 131 de la Constitución de 1917.

Unos cuantos años después, en 1905, se expidió la Tarifa de la Ordenanza General de Aduanas de los Estados Unidos Mexicanos, conforme a un decreto del 20 de junio del mismo año y que empezaría a regir el 1 de septiembre de 1905.

VI. LA CONSTITUCIÓN DE 1917

Como señalamos, la facultad originaria en materia de comercio exterior se encuentra en la fracción XXIX del artículo 73 constitucional, si bien, el artículo 131 habrá de ser determinante en la materia a partir de la reforma de 1951 .

El texto original de la Constitución de 1917 establecía:

"Art. 131.- Es facultad privativa de la federación, gravar las mercancías que se importen o exporten o que pasen de tránsito por el territorio nacional, así como reglamentar en todo tiempo, y aún prohibir por motivos de seguridad o de policía, la circulación en el interior de la República, de toda clase de efectos, cualquiera que sea su procedencia; pero sin que la misma Federación pueda establecer ni dictar en el Distrito y Territorios Federales, los impuestos y leyes que expresan las fracciones VI y VII del Art. 117."

Este artículo se ha reformado en tres ocasiones:

La primera publicada en el Diario Oficial de la Federación del 28 de marzo de 1951 fue de gran trascendencia pues le añadió un párrafo segundo que estableció:

El Ejecutivo podrá ser facultado por el Congreso de la Unión para aumentar, disminuir o suprimir las cuotas de las tarifas de exportación e importación, expedidas por el propio Congreso, y para crear otras; así como para restringir y para prohibir las importaciones, las exportaciones y el tránsito de productos, articulos y efectos, cuando lo estime urgente, a fin de regular el comercio exterior, la economía del pais, la estabilidad de la producción nacional, o de realizar 
cualquiera otro propósito, en beneficio del país. El propio Ejecutivo al enviar al Congreso el Presupuesto Fiscal de cada año, someterá a su aprobación el uso que hubiese hecho de la facultad concedida.

Con la reforma de 1951 se estableció una excepción más al principio de división de poderes, al darle facultades legislativas excepcionales al Ejecutivo en materia arancelaria que han sido esenciales para el desarrollo de la política comercial de México hasta el día de hoy.

La segunda reforma se publicó en el Diario Oficial de la Federación del 8 de octubre de 1974, esta vez al primer párrafo para quedar:

Es facultad privativa de la Federación gravar las mercancías que se importen o exporten, o que pasen de tránsito por el territorio nacional, así como reglamentar en todo tiempo y aún prohibir, por motivos de seguridad o de policia, la circulación en el interior de la República de toda clase de efectos, cualquiera que sea su procedencia; pero sin que la misma Federación pueda establecer, ni dictar, en el Distrito Federal, los impuestos y leyes que expresan las fracciones VI y VII del artículo 117.

La tercera reforma, mucho más reciente, publicada en el Diario Oficial de la Federación del 29 de enero de 2016 suprimió la segunda parte del primer párrafo que disponía: "pero sin que la misma Federación pueda establecer, ni dictar, en el Distrito Federal, los impuestos y leyes que expresan las fracciones VI y VII del artículo 117 "

A inicios del siglo XX México seguía una política en materia de comercio exterior tradicionalmente proteccionista y cerrada a la competencia internacional, lo que llevó al desarrollo de una planta industrial que requería y requiere aún de constantes apoyos.

En 1929 se busca un modelo económico nacionalista, afectado por la gran depresión estadounidense de ese año. Este sistema que abarca de 1929 a 1940 será el fundamento del proceso de industrialización en México, hasta que con la Segunda Guerra Mun- 
dial se pasará al sistema de sustitución de importaciones, ${ }^{29}$ vía un proteccionismo indiscriminado en donde el Estado participa como un elemento fundamental en la regulación de la economía nacional, si bien no se puede hablar de una economía cerrada totalmente al exterior. Se busca obtener tasas máximas de crecimiento, incremento del empleo y mejorar el nivel de vida de la población. ${ }^{30}$

Si bien, aunque en 1940 las exportaciones de mercancías ascendían a 94.4 millones de dólares, llegando en 1946 a 318.5 millones de dólares, la balanza comercial fue desfavorable para el país, pese a las oportunidades resultantes de la Segunda Guerra Mundial. ${ }^{31}$

Para 1950 la sustitución de importaciones de bienes de consumo no duradero se consideró agotada, iniciándose la de bienes intermedios y de capital. La protección otorgada por el sistema se basó en el manejo del tipo de cambio, altas cargas a la importación de bienes del exterior y controles cuantitativos y permisos previos de importación que llegaron a ser necesarios para el 80\% de las importaciones.

Lo anterior logró eliminar la competencia externa, teniendo como consecuencia una producción en muchos casos ineficiente y de alto costo que impidió una penetración efectiva en el mercado de exportación.

${ }^{29}$ Cruz Miramontes, Rodolfo, "El comercio exterior de México en la última década", Furídica, Anuario del Departamento de Derecho de la Universidad Iberoamericana, México, UIA, Núm. 29, 1999, págs. 158-159.

30 Sobre el tema véase Villarreal, René, "Del proyecto de crecimiento y sustitución de importaciones al desarrollo y sustitución de exportaciones", El comercio exterior de México, México, Instituto Mexicano de Comercio Exterior, Academia de Arbitraje y Comercio Internacional, Siglo veintiuno editores, tomo I, 1982.

${ }^{31}$ Ortíz Wadgymar, Arturo, Comercio exterior de México en el siglo XX, México, Instituto de Investigaciones Económicas, UNAM, Miguel Angel Porrúa, 2001, pág. 33 . 
La imposibilidad de acceder a recursos del exterior vía exportaciones obligó al país a recurrir cada vez más al financiamiento externo, lo que se reflejó negativamente en la balanza de pagos. ${ }^{32}$

En 1970 se diseñó un plan de apoyo estructural a las exportaciones con la creación y fortalecimiento de organismos como el Instituto Mexicano de Comercio Exterior (IMCE), el Banco Nacional de Comercio Exterior (BANCOMEXT), la Comisión para la Protección del Comercio Exterior (COMPROMEX), la Comisión Nacional de Fletes Marítimos (CONAFLEMAR), la Asociación Mexicana de Usuarios del Transporte Marítimo A.C. (AMUTMAC), la Academia Mexicana de Arbitraje y Comercio Internacional (ADACI), el Comité (ad-hoc) para la defensa de las Exportaciones, el Comité de Compras del Sector Público y la Comisión nacional de Comercio Exterior. Si bien no fueron suficientes, sí constituyeron un esfuerzo notable para ordenar y fomentar el comercio exterior y fomento industrial de México.

Se crearon en ese momento toda una gama de estímulos al comercio exterior como son los Programas de Importación Temporal (PITEX), el Régimen de Maquiladoras, los Certificados de Promoción Fiscal (CEPROFIS), las Empresas Altamente Exportadoras (ALTEX), etc.

Claro esta que el símbolo del apoyo y promoción del comercio exterior fue el IMCE. ${ }^{33}$

Este sistema de apoyos sufrió constantes ataques en los mercados internacionales a los que acudían productos y bienes, sobre todo

${ }^{32}$ Cruz Miramontes Rodolfo, op. cit., nota 8.

${ }^{33}$ Creación de Carlos Torres Manso y de Julio Faesler, el IMCE nace mediante ley publicada en el Diario Oficial de la Federación de fecha 31 de diciembre de 1970. Sobre el Instituto véase Gazol Santafé, Antonio (Ed.), El nacimiento del IMCE, México, 1971, Coleccion Selecciones y Documentos sobre la Actividad Económica en Latinoamérica. 
por parte de las autoridades estadounidenses, lo que culminó, a partir de 1985, en una serie de cambios que los llevaron hasta su casi desaparición (como ejemplo, los CEPROFIS que se extinguieron entre agosto y diciembre de 1987), al firmarse en ese año lo que se conoció como el "Entendimiento sobre la prueba del daño", por el que se cancelaron los subsidios otorgados a las exportaciones mexicanas existentes a la fecha y la concesión por parte de los Estados Unidos "...de la llamada "prueba del daño" que no recibiríamos al no estar comprendidos en alguna de las hipótesis legales a que se refiere la Sección Primera de la Trade Act of 1974." "34

Aunado a lo anterior, el gobierno de México decidió desaparecer al Instituto Mexicano de Comercio Exterior ${ }^{35}$ e ingresar al GATT ${ }^{36}$ en 1986, liberalizando para el año de 1987 su comercio de manera notable, para contar entre 1988 y 1992 con un superávit comercial y en cuenta corriente, y una participación cada vez más importante de la política comercial en materia de combate a la inflación. Sin embargo, el ingreso de México al GATT no produjo las esperadas nuevas inversiones a largo plazo, aunado a que las medidas proteccionistas estadounidenses frente a las exportaciones mexicanas no solo continuaron en vigor, sino que se han ido incrementando y en ciertos casos, de espaldas a los principios y reglas del GATT.

${ }^{34}$ Cruz Miramontes, Rodolfo, op. cit., nota 8, pág. 160.

${ }^{35}$ Lo que se lleva a cabo en diciembre de 1985, véase Decreto por el que se abroga la Ley de crea al Instituto Mexicano de Comercio Exterior, en el Diario Oficial de la Federación de 6 de diciembre de 1985 .

${ }^{36}$ Ver los decretos de fechas 29 de octubre y 26 de noviembre de 1986 sobre aprobación y promulgación del Protocolo de Adhesión de México al GATT. Sobre la polémica existente previa a la adhesión de México al acuerdo, véase el capítulo VII de la obra El comercio exterior de México, México, Instituto Mexicano de Comercio Exterior, Academia de Arbitraje y Comercio Internacional, Siglo veintiuno editores, tomo II, 1982. 
A partir de 1985 la apertura comercial buscaba corregir las distorsiones económicas generadas por la estrategia de sustitución de importaciones. Para el año de 1989, México había liberalizado su comercio de manera notable, pues “...de 8080 fracciones arancelarias prevalecientes en 1982 sujetas a permisos de importación para 1989 solo la requerían 202." 37 Entre 1988 y 1992 México contó con un superávit comercial y en cuenta corriente, con un rol cada vez más importante de la política comercial en materia de combate a la inflación. Sin embargo, el ingreso de México al GATT no produjo las esperadas nuevas inversiones a largo plazo, aunado a que las medidas proteccionistas estadounidenses frente a las exportaciones mexicanas continuaron en vigor. ${ }^{38}$

Se buscó afianzar el ingreso de inversiones al país estrechando las relaciones económicas con Estados Unidos, de ahí el inicio en su momento, de las negociaciones para la suscripción del Tratado de Libre Comercio de América del Norte (TLCAN) ${ }^{39}$ y que, con el antecedente del Tratado celebrado con la República de Chile ${ }^{40}$, llevarían a negociar tratados con Costa Rica ${ }^{41}$, Venezuela y Colom-

${ }^{37}$ Cruz Miramontes, Rodolfo, op. cit., nota 8, pág. 160.

${ }^{38}$ Ver Ramírez de la O, Rogelio, "El Tratado de Libre Comercio de América del Norte desde una perspectiva mexicana”, en Globerman, Steven y Walker, Michael (Comp.), El TLC. Un enfoque trinacional, Trad. Mónica Utrilla, México, Fondo de Cultura Económica, 1994, págs. 86-87.

${ }^{39}$ Entró en vigor el 1 de enero de 1994.

${ }^{40}$ Que entró en vigor en enero de 1992. Posteriormente se negociaría un Tratado de Libre Comercio con dicho país, firmado el 17 de abril de 1998, publicado en el Diario Oficial de la Federación del 28 de julio del 1999.

${ }^{41}$ Entró en vigor el 1 de enero de 1995. 
bia $^{42}$, Bolivia ${ }^{43}$, Nicaragua ${ }^{44}$, la Unión Europea ${ }^{45}$ Israel $^{46}$, Honduras, El Salvador y Guatemala ${ }^{47}$, Uruguay ${ }^{48}$, el Acuerdo Europeo de Libre Comercio ${ }^{49}$, Japón ${ }^{50}$ y el Acuerdo de Integración Comercial con Perú. ${ }^{51}$

Sumado a lo anterior, se negociaron acuerdos de alcance parcial de complementación económica con Argentina y Brasil ${ }^{52}$. En el mes de julio de 2002 se suscribió el Acuerdo de Complementación Económica 54, que establece el compromiso de establecer una zona de libre comercio entre México y el Mercosur. Actualmente está en vigor el ACE-55 ${ }^{53}$ México - Mercosur (Sector Automotor) con un Primer protocolo adicional al Apéndice 1 del ACE 55 (México - Argentina). El Acuerdo comprende los celebrados o que se celebren entre México y ese bloque, así como los que celebre México con cada uno de los países miembros.

${ }^{42}$ Entró en vigor el 1 de enero de 1995.

${ }^{43}$ Entró en vigor el 1 enero de 1995. Posteriormente se negociaría el Acuerdo de Complementación Económica México-Bolivia No. 66 que entró en vigor el 07 de junio de 2010.

${ }^{44}$ Entró en vigor el 1 de junio de 1998.

${ }^{45}$ Entró en vigor el 1 de julio de 2000.

${ }^{46}$ Entró en vigor el 1 de julio de 2000. Publicado en el Diario Oficial de la Federación del 28 de junio del 2000.

${ }^{47}$ Entró en vigor el 1 de enero de 2001.

${ }^{48}$ Publicado en el Diario Oficial de la Federación del 14 de julio del 2004.

${ }^{49}$ Entró en vigor el 1 de julio de 2001. Publicado en el Diario Oficial de la Federación del 29 de junio del 2001.

${ }^{50}$ Entró en vigor el 1 de abril de 2005.

${ }^{51}$ Entró en vigor el 01 de febrero de 2012.

${ }^{52}$ Se trata del ACE-53 México-Brasil en vigor a partir del 2 de mayo de 2003. Tiene un Primer Protocolo Adicional (Solución de Controversias, que no ha entrado en vigor) y un Segundo Protocolo Adicional (Certificado de origen- cupos).

${ }^{53}$ Vigente a partir del 1 de enero de 2003. 
A este respecto, explicaba el Secretario de Economía Ildefonso Guajardo en 2016, que para hacer frente a los retos de los mercados globales, en los últimos tres años México ha optado por una ambiciosa política comercial que abarca los cuatro puntos cardinales: "al norte, consolidar la integración en el marco del TLCAN; al este, modernizar los tratados de libre comercio con la Unión Europea y la Asociación Europea de Libre Comercio (AELC) y negociar nuevos acuerdos en Medio Oriente (Turquía y Jordania); al Oeste, el Acuerdo de Asociación Transpacífico (TPP, por sus siglas en inglés), y al Sur, en América Latina, la profundización del Acuerdo Comercial con Brasil así como iniciativas de gran vanguardia como la Alianza del Pacífico (AP)". ${ }^{54}$ Sigue pendiente el desarrollo de las relaciones económicas y comerciales con el continente africano. ${ }^{55}$

El Acuerdo de Asociación Transpacífico o TPP, después TPP-11 y finalmente Tratado Integral y Progresista de Asociación Transpacifico (CPTPP $)^{56}$ ha sido, sin duda al día de hoy, la negociación comercial multilateral más importante con posibles afectaciones al mercado regional de Norte América, en donde en un inicio los tres Estados Parte del TLCAN, ahora solamente Canadá y México hasta que se reincorporen los Estados Unidos de América, "tendrán dos con-

${ }^{54}$ Guajardo Villarreal, Ildefonso, "La dimensión económica de la Alianza del Pacífico: una perspectiva mexicana", en Revista Mexicana de Política Exterior, México, Instituto Matías Romero, Secretaría de Relaciones Exteriores, núm. 106, enero-abril de 2016, pág. 23. Sobre la Alianza del Pacífico véase también Cruz Barney, Oscar, "La solución de controversias entre Partes en la Alianza del Pacífico", en Revista Mexicana de Política Exterior, México, Instituto Matías Romero, Secretaría de Relaciones Exteriores, Núm. 114, Septiembre-Diciembre, 2018.

${ }^{55}$ Véase De Maria y Campos Castelló, Mauricio, “África: una oportunidad para la política exterior mexicana”, en Comercio Exterior, México, Bancomext, Nueva Época, Número 17, enero-marzo, 2019, Págs. 8 y sigs.

${ }^{56}$ Véase Cruz Barney, Oscar, El Tratado Integral y Progresista de Asociación Transpacífico (CPTPP/TIPAT) y la Solución de Controversias en los Acuerdos Comerciales Internacionales Firmados por México, México, Tirant Lo Blanch, 2018. 
juntos de reglas comerciales que podrán aplicar para su relación trilateral de forma distinta según les convenga." $" 57$

Recientes cambios en la política económica y comercial de los Estados Unidos de América obligan a México a replantear su estrategia frente al exterior diversificando, no solamente en la red de tratados sino en el intercambio comercial efectivo, sus relaciones económicas internacionales. ${ }^{58}$ Ejemplo claro es la modernización del TLCAN que dió como resultado el T-MEC. ${ }^{59}$

La legislación secundaria, reglamentaria del Artículo 131 Constitucional se inicia con la Ley Reglamentaria del Segundo Párrafo del artículo 131 de la Constitución Política de los Estados Unidos Mexicanos publicada en el Diario Oficial de la Federación del 5 de enero de 1961. Esta Ley fue derogada por la Ley Reglamentaria del Artículo 131 de la Constitución Política de los Estados Unidos Mexicanos publicada en el Diario Oficial de la Federación del 13 de enero de $1986 .{ }^{60}$

${ }^{57}$ Noricumbo Robles, Carlos, et. al., México y el Acuerdo de Asociación Transpacífico (TPP): Contenidos, Implicaciones y Consideraciones Esenciales, México, Instituto Belisario Domínguez, Senado de la República, Serie Cuaderno de Investigación TPP-2, Pág. 86.

${ }^{58}$ En este sentido véase De Maria y Campos Castelló, Mauricio et. al. (Coords.), Visión de conjunto y sintesis de retos y propuestas, México, Centro Tepoztlán, El Colegio de México, Foro Consultivo Científico y Tecnológico., A.C., 2019, pág. 22.

${ }^{59}$ En este sentido Cruz Barney, Oscar, "TLC: mitos y realidades sobre la salida de EUA", en IDC Asesor Furídico y Fiscal, México, Grupo Expansión, Núm. 386, Año XXX, 4 época, 15 de enero de 2017 y Cruz Barney, Oscar, "Renegociación del TLCAN", en IDC Asesor furídico y Fiscal, México, Grupo Expansión, Núm. 398, Año XXX, 4a época, 15 de Julio de 2017. Asimismo, Cruz Barney, Oscar, La modernización del TLCAN en el contexto de las relaciones comerciales entre México y los Estados Unidos de América, México, UNAM, Instituto de Investigaciones Jurídicas, 2018, y Cruz Barney, Oscar y Reyes Díaz, Carlos, El T-MEC/USMCA: solución de controversias, remedios comerciales e inversiones, México, UNAM, Instituto de Investigaciones Jurídicas, Opiniones Técnicas sobre temas de relevancia Nacional, 2018.

${ }^{60}$ Sobre esta se publicó una interesante obra: Barra Mexicana, Colegio de Abogados, La nueva ley sobre comercio exterior, México, Porrúa, 1987. 
La Ley de Comercio Exterior vigente fue publicada en el Diario Oficial de la Federación del 27 de julio de 1993 y su última reforma fue del 21 de diciembre de 2006. En su Artículo $1^{\circ}$ se aclara que la Ley tiene por objeto regular y promover el comercio exterior, incrementar la competitividad de la economía nacional, propiciar el uso eficiente de los recursos productivos del país, integrar adecuadamente la economía mexicana con la internacional, defender la planta productiva de prácticas desleales del comercio internacional y contribuir a la elevación del bienestar de la población. Asimismo, se determina que sus disposiciones son de orden público y de aplicación en toda la República, sin perjuicio de lo dispuesto por los tratados o convenios internacionales de los que México sea parte. La aplicación e interpretación de sus disposiciones corresponden, para efectos administrativos, al Ejecutivo Federal por conducto de la Secretaría de Economía.

Conforme a la Ley de Comercio Exterior, las facultades del Ejecutivo Federal incluyen: I. Crear, aumentar, disminuir o suprimir aranceles, mediante decretos publicados en el Diario Oficial de la Federación, de conformidad con lo establecido en el artículo 131 de la Constitución Política de los Estados Unidos Mexicanos; II. Regular, restringir o prohibir la exportación, importación, circulación o tránsito de mercancías, cuando lo estime urgente, mediante decretos publicados en el Diario Oficial de la Federación, de conformidad con el artículo 131 de la Constitución Política de los Estados Unidos Mexicanos; III. Establecer medidas para regular o restringir la exportación o importación de mercancías a través de acuerdos expedidos por la Secretaría o, en su caso, conjuntamente con la autoridad competente, y publicados en el Diario Oficial de la Federación; IV. Establecer medidas para regular o restringir la circulación o tránsito de mercancías extranjeras por el territorio nacional procedentes del y destinadas al exterior a través de acuerdos 
expedidos por la autoridad competente y publicados en el Diario Oficial de la Federación; V. Conducir negociaciones comerciales internacionales a través de la Secretaría, sin perjuicio de las facultades que correspondan a otras dependencias del Ejecutivo Federal; VI. Coordinar, a través de la Secretaría, la participación de las dependencias y entidades de la Administración Pública Federal y de los gobiernos de los estados en las actividades de promoción del comercio exterior, así como concertar acciones en la materia con el sector privado, y VII. Coordinar, a través de la Secretaría, que las dependencias y entidades de la Administración Pública Federal que administren o controlen una restricción o regulación no arancelaria se encuentren interconectadas electrónicamente con la Secretaría y con la Secretaría de Hacienda y Crédito Público.

\section{LA DISCUSIÓN Y APROBACIÓN DE LOS TRATADOS COMERCIA- LES INTERNACIONALES}

El marco jurídico para la discusión y en su caso aprobación de un tratado comercial internacional se integra por las disposiciones constitucionales que facultan tanto al Poder Ejecutivo Federal como al Legislativo en materia de comercio exterior, celebración y aprobación de tratados, como en la Ley sobre la celebración de tratados y la Ley sobre Aprobación de Tratados Internacionales en Materia Económica.

A nivel constitucional, recordemos que conforme al Artículo 117 de la Carta Magna, los Estados no pueden, en ningún caso celebrar alianza, tratado o coalición con otro Estado ni con las Potencias extranjeras. Dicha tarea corresponde al Ejecutivo Federal. Asimismo, conforme a la fracción XXIX del Artículo 73 Constitucional, el Congreso tiene facultad para establecer contribuciones sobre el comercio exterior. 
En el Artículo 76 al tratar de las facultades exclusivas del Senado se incluye la de analizar la política exterior desarrollada por el Ejecutivo Federal con base en los informes anuales que el Presidente de la República y el Secretario del Despacho correspondiente rindan al Congreso. Además, aprobar los tratados internacionales y convenciones diplomáticas que el Ejecutivo Federal suscriba, así como su decisión de terminar, denunciar, suspender, modificar, enmendar, retirar reservas y formular declaraciones interpretativas sobre los mismos;

La negociación de los tratados como sabemos corresponde conforme al Artículo 89, al presidente de la República al ser responsable de dirigir la política exterior y celebrar tratados internacionales, así como terminar, denunciar, suspender, modificar, enmendar, retirar reservas y formular declaraciones interpretativas sobre los mismos, sometiéndolos a la aprobación del Senado. En la conducción de tal política, el titular del Poder Ejecutivo debe observar los siguientes principios normativos:

- La autodeterminación de los pueblos;

- La no intervención;

- La solución pacífica de controversias;

- La proscripción de la amenaza o el uso de la fuerza en las relaciones internacionales;

- La igualdad jurídica de los Estados;

- La cooperación internacional para el desarrollo;

- El respeto, la protección y promoción de los derechos humanos y

- La lucha por la paz y la seguridad internacionales;

Como adelantamos, el marco jurídico secundario aplicable a la discusión de un tratado internacional de comercio en México está contenido en la Ley sobre la celebración de tratados publicada en el Diario Oficial de la Federación 2 de enero de 1992 y en la Ley sobre la aprobación de tratados internacionales en materia económica se publicó en el Diario Oficial de la Federación el 2 de septiembre de 2004. 
La Ley sobre la celebración de tratados, que ha sido ya en varias ocasiones cuestionada respecto de su constitucionalidad ${ }^{61}$, tiene por objeto regular la celebración de tratados y acuerdos interinstitucionales en el ámbito internacional. Los tratados sólo podrán ser celebrados entre el Gobierno de los Estados Unidos Mexicanos y uno o varios sujetos de derecho internacional público. Contempla los denominados "acuerdos interinstitucionales" que sólo podrán ser celebrados entre una dependencia u organismos descentralizados de la Administración Pública Federal, Estatal o Municipal y uno o varios órganos gubernamentales extranjeros u organizaciones internacionales. En su Artículo 2 define el término Tratado como "el convenio regido por el derecho internacional público, celebrado por escrito entre el Gobierno de los Estados Unidos Mexicanos y uno o varios sujetos de Derecho Internacional Público, ya sea que para su aplicación requiera o no la celebración de acuerdos en materias específicas, cualquiera que sea su denominación, mediante el cual los Estados Unidos Mexicanos asumen compromisos" y "Aprobación" como el acto por el cual el Senado aprueba los tratados que celebra el Presidente de la República.

La Ley sobre la aprobación de tratados internacionales en materia económica tiene como objeto reglamentar el artículo 93 de la Constitución General de la República en materia de las facultades constitucionales del Senado de requerir información a los secretarios de estado, jefes de departamento administrativo, así como a los directores de los organismos descentralizados competentes sobre la negociación,

${ }^{61}$ Así, los textos de López Mata, Rosendo, "Notas para el análisis sobre la Constitucionalidad de algunas disposiciones contenidas en la Ley sobre la celebración de Tratados", en Furídica, Anuario del Departamento de Derecho de la Universidad Iberoamericana, México, No. 24, Vol. I, 1995; Sepúlveda Iguíniz, Ricardo J., "Análisis constitucional de la ley sobre la celebración de Tratados", en Revista de Investigaciones furídicas, México, Escuela Libre de Derecho, Año 18, No. 18, 1994; Trigueros Gaisman, Laura, "Comentarios en torno a la ley sobre la celebración de tratados", en Alegatos, México, No. 21, Mayo-Agosto, 1992. Véase también Palacios Treviño, Jorge, Análisis crítico jurídico de la ley sobre la celebración de Tratados, México, Secretaría de Relaciones Exteriores, Dirección General de Acervo Histórico Diplomático, 2000. 
celebración y aprobación de tratados relacionados con el comercio de mercancías, servicios, inversiones, transferencia de tecnología, propiedad intelectual, doble tributación y cooperación económica.

La Ley plantea la obligación del Ejecutivo de presentar un Informe de Inicio de Negociaciones. ${ }^{62}$

Conforme al Artículo 3 de dicha Ley, para la aprobación de un tratado se observarán los siguientes objetivos generales:

I. Contribuir a mejorar la calidad de vida y el nivel de bienestar de la población mexicana;

II. Propiciar el aprovechamiento de los recursos productivos del país;

III. Promover el acceso de los productos mexicanos a los mercados internacionales;

IV. Contribuir a la diversificación de mercados;

V. Fomentar la integración de la economía mexicana con la internacional y contribuir a la elevación de la competitividad del país, y

VI. Promover la transparencia en las relaciones comerciales internacionales y el pleno respeto a los principios de política exterior de la fracción X del artículo 89 de la Constitución Política de los Estados Unidos Mexicanos.

Asimismo, y conforme al Artículo 4 del citado ordenamiento, para la aprobación de un tratado se deberá tener congruencia con los siguientes objetivos particulares según proceda:

I. En materia de solución de controversias:

a) Otorgar a los mexicanos y extranjeros que sean parte en la controversia el mismo trato conforme al principio de reciprocidad internacional;

b) Asegurar a las partes la garantía de audiencia y el debido ejercicio de sus defensas, $y$

c) Garantizar que la composición de los órganos de decisión asegure su imparcialidad;

${ }^{62}$ Consultable en http://infosen.senado.gob.mx/sgsp/gaceta/62/1/2012-11-27-1/assets/documentos/INFORME_SE.pdf. 
II. En materia de prácticas desleales de comercio exterior:

a) Fomentar la libre concurrencia y buscar las sanas prácticas de competencia, y

b) Prever y promover mecanismos para contrarrestar los efectos de las prácticas desleales de comercio de los países con los que se contrate;

III. Fomentar el respeto de los derechos de propiedad intelectual;

IV. Impulsar el fomento y la protección recíproca de las inversiones y las transferencias de tecnología, generación, difusión y aplicación de los conocimientos científicos y tecnológicos que requiere el desarrollo nacional;

V. Impulsar la eliminación o reducción de obstáculos innecesarios al comercio que sean incompatibles con la ley y con los compromisos internacionales;

VI. Prever que las normas de los tratados consideren las asimetrías, diferencias y desequilibrios, así como las medidas correspondientes para compensarlas, y

VII. Los demás objetivos que correspondan a la naturaleza del tratado.

Los Artículos 9 a 12 contemplan el procedimiento a seguir ante y por el Senado de la República en el proceso de aprobación o no del tratado internacional correspondiente. Así, para la aprobación de algún tratado ya firmado, el texto deberá someterse al Senado junto con los siguientes documentos:

I. Un escrito con todas las acciones administrativas para aplicar los objetivos que correspondan conforme al tratado de que se trate;

II. Una explicación de cómo la aprobación del tratado afectará las leyes y reglamentos de México;

III. Los rubros que México concedió durante la negociación;

IV. La forma en que se cumplirán los objetivos que correspondan conforme al tratado firmado;

V. La manera en que el tratado cumple con los intereses de México, y

VI. Las reservas que los países miembros del tratado establecieron y las razones. 
Para la aprobación del tratado, el Senado de la República, o en su caso la Comisión Permanente deberán turnar el mismo a las comisiones competentes, en la sesión siguiente a la fecha en que el Ejecutivo Federal lo haya sometido al Senado.

Cabe destacar que los ciudadanos y las organizaciones empresariales, ciudadanas y sindicales podrán emitir su opinión ante el Senado de la República. Las comunicaciones entre ciudadanos, organizaciones y las comisiones correspondientes podrán ser orales en audiencia o por escrito. En todo caso, serán públicas, salvo disposición legal en contrario.

El Senado de la República, a través de sus comisiones, deberá escuchar y tomar en cuenta las propuestas que le hagan llegar o que presenten los Gobiernos y Congresos Locales.

Cabe tener presente que conforme al Artículo 105 Constitucional, al tratar de las acciones de inconstitucionalidad que tengan por objeto plantear la posible contradicción entre una norma de carácter general y la Constitución, éstas podrán ejercitarse, dentro de los treinta días naturales siguientes a la fecha de publicación de la norma, por el equivalente al treinta y tres por ciento de los integrantes del Senado, en contra de los tratados internacionales celebrados por el Estado Mexicano.

\section{Consideración final}

Las facultades del Poder Ejecutivo en materia de comercio exterior tienen su expresión más destacable en el artículo 131 Constitucional. Ahora más que nunca quizás, el Ejecutivo Federal deberá hacer uso de las mismas, ante el panorama complejo que atraviesa el comercio mundial.

La defensa de la planta productiva nacional y una política comercial agresiva hacia el exterior es necesaria a fin de mantener e incrementar la presencia de productos mexicanos en el exterior. 
Se hace cada vez más necesaria la estructuración de un esquema de promoción de exportaciones, que ayude a la integración de cadenas productivas para el comercio exterior y auxilie en la apertura de mercados en el exterior. Tarea que no puede dejarse en manos no expertas en la materia.

El aprovechamiento de los mercados existentes y la apertura de nuevos destinos para la producción mexicana es indispensable. Destinos como África se mantienen todavía como pendientes en la agenda económica nacional.

VIII. Fuentes

1. Bibliografía

Alonso Álvarez, Luís, "El impacto de las reformas borbónicas en las redes comerciales. Una visión desde el Pacífico hispano, 1762-1815", en Antonio Ibarra y Guillermina del Valle Pavón, Redes sociales e instituciones comerciales en el imperio español, siglos XVII a XIX, México, Instituto Mora, Facultad de Economía, UNAM, 2007.

Barra Mexicana, Colegio de Abogados, La nueva ley sobre comercio exterior, México, Porrúa, 1987.

Cruz Barney, Oscar, "Artículo 131", en Arriola, Juan Federico (Coord.), Constitución Política Mexicana en su Centenario, México, Editorial Trillas, 2017.

, Oscar, El comercio exterior de México, 1821-1928, México, Instituto de Investigaciones Jurídicas, UNAM, 2005.

, Oscar, El Tratado Integral y Progresista de Asociación Transpacifico (CPTPP/TIPAT) y la Solución de Controversias en los Acuerdos Comerciales Internacionales Firmados por México, México, Tirant Lo Blanch, 2018.

, Oscar, La modernización del TLCAN en el contexto de las relaciones comerciales entre México y los Estados Unidos de América, México, UNAM, Instituto de Investigaciones Jurídicas, 2018. 
Cruz Barney, Oscar y Reyes Díaz, Carlos, El T-MEC/USMCA: solución de controversias, remedios comerciales e inversiones, México, UNAM, Instituto de Investigaciones Jurídicas, Opiniones Técnicas sobre temas de relevancia Nacional, 2018.

De Maria y Campos Castelló, Mauricio et. al. (Coords.), Visión de conjunto y sintesis de retos y propuestas, México, Centro Tepoztlán, El Colegio de México, Foro Consultivo Científico y Tecnológico., A.C., 2019.

Gazol Santafé, Antonio (Ed.), El nacimiento del IMCE, México, Coleccion Selecciones y Documentos sobre la Actividad Económica en Latinoamérica, 1971.

Herrera Canales, Inés, El comercio exterior de México 1821-1875, México, El Colegio de México, 1977.

Ibarra Bellón, Araceli, El comercio y el poder en México, 1821-1864. La lucha por las fuentes financieras entre el Estado central y las regiones, México, Fondo de Cultura Económica, Universidad de Guadalajara, 1998.

Montenegro Duque, Ángel, Historia de España, Madrid, ed. Gredos, tomo $10,1991$.

Muro, Luis, "Revillagigedo y el comercio libre (1791-1792)", Extremos de México. Homenaje a don Daniel Cosío Villegas, México, El Colegio de México, 1971.

Noricumbo Robles, Carlos, et. al., México y el Acuerdo de Asociación Transpacifico (TPP): Contenidos, Implicaciones y Consideraciones Esenciales, México, Instituto Belisario Domínguez, Senado de la República, Serie Guaderno de Investigación TPP-2.

Ortiz de la Tabla Ducasse, Javier, Comercio exterior de Veracruz 1778-1821 crisis de dependencia, Sevilla, Escuela de Estudios Hispanoamericanos de Sevilla, G.S.I.G., 1978.

Ortiz Wadgymar, Arturo, Comercio exterior de México en el siglo XX, México, Instituto de Investigaciones Económicas, UNAM, Miguel Ángel Porrúa, 2001. 
Palacios Treviño, Jorge, Análisis crítico jurídico de la ley sobre la celebración de Tratados, México, Secretaría de Relaciones Exteriores, Dirección General de Acervo Histórico Diplomático, 2000.

Ramírez de la O, Rogelio, "El Tratado de Libre Comercio de América del Norte desde una perspectiva mexicana", en Globerman, Steven y Walker, Michael (Comp.), El TLC. Un enfoque trinacional, Trad. Mónica Utrilla, México, Fondo de Cultura Económica, 1994.

Souto Mantecón, Matilde, "El Consulado de Veracruz ante el comercio extranjero: 1799-1819”, en Meyer Cosío, Rosa María (coord.), Identidady prácticas de los grupos de poder en México, siglos XVII-XIX, México, Instituto Nacional de Antropología e Historia, 1999, colección científica, serie historia.

Villarreal, René, "Del proyecto de crecimiento y sustitución de importaciones al desarrollo y sustitución de exportaciones", El comercio exterior de México, México, Instituto Mexicano de Comercio Exterior, Academia de Arbitraje y Comercio Internacional, Siglo veintiuno editores, tomo I, 1982.

\section{Hemerografía}

Alfonso Mola, Marina, "La Marina Mercante colonial en la legislación borbónica (1700-1828)", en Martínez Shaw, Carlos (Ed.), El derecho y el mar en la España moderna, Granada, Universidad de Granada, Centre d'estudis d'historia moderna Pierre Vilar, 1995.

Cruz Barney, Oscar, "La solución de controversias entre Partes en la Alianza del Pacífico", en Revista Mexicana de Política Exterior, México, Instituto Matías Romero, Secretaría de Relaciones Exteriores, Núm. 114, septiembre-diciembre, 2018.

, Oscar, "Renegociación del TLCAN", en IDC Asesor Furídico y Fiscal, México, Grupo Expansión, Núm. 398, Año XXX, 4ª época, 15 de Julio de 2017. 
, "TLC: mitos y realidades sobre la salida de EUA", en IDC Asesor Furídico y Fiscal, México, Grupo Expansión, Núm. 386, Año XXX, $4^{a}$ época, 15 de enero de 2017.

Cruz Miramontes, Rodolfo, "El comercio exterior de México en la última década", Furídica, Anuario del Departamento de Derecho de la Universidad Iberoamericana, México, UIA, Núm. 29, 1999.

De María y Gampos Castelló, Mauricio, “África: una oportunidad para la política exterior mexicana", en Comercio Exterior, México, Bancomext, Nueva Época, Número 17, enero-marzo, 2019.

Gortari Palacios, Hira de, "El comercio novohispano a través de Veracruz", Historia Mexicana, México, El Colegio de México, núm. 67, enero-marzo, 1968.

Guajardo Villarreal, Ildefonso, "La dimensión económica de la Alianza del Pacífico: una perspectiva mexicana”, en Revista Mexicana de Política Exterior, México, Instituto Matías Romero, Secretaría de Relaciones Exteriores, núm. 106, enero-abril de 2016.

Langue, Frédérique, "Hombres e ideas de la ilustración en dos ciudades consulares: Caracas y Veracruz", Historia Mexicana, México, El Colegio de México, núm. 179, enero-marzo, 1996.

López Mata, Rosendo, "Notas para el análisis sobre la Constitucionalidad de algunas disposiciones contenidas en la Ley sobre la celebración de Tratados", en Furídica, Anuario del Departamento de Derecho de la Universidad Iberoamericana, México, No. 24, Vol. I, 1995.

Muñoz Pérez, José "El comercio de Indias bajo los Austrias y los tratadistas españoles del siglo XVII", Revista de Indias, núm. 68, año XVII, abril-junio, 1957.

Muñoz, Laura, "Los puertos mexicanos del Golfo durante los primeros años del México independiente: fuentes para su estudio", en América Latina en la Historia Económica. Boletín de Fuentes, México, Instituto de Investigaciones Dr. José María Luis Mora, enero-junio, Número 21, 2004. 
Sepúlveda Iguíniz, Ricardo J., "Análisis constitucional de la ley sobre la celebración de Tratados", en Revista de Investigaciones furídicas, México, Escuela Libre de Derecho, Año 18, No. 18, 1994.

Trigueros Gaisman, Laura, "Comentarios en torno a la ley sobre la celebración de tratados", en Alegatos, México, No. 21, mayo-agosto, 1992.

3. Legisgrafía

Arancel General de Aduanas de 5 de octubre de 1820, en Colección de los decretos y órdenes generales de la primera legislatura de las Cortes ordinarias de 1820 y 1821, desde 6 de julio hasta 9 de noviembre de 1820. Mandada publicar de orden de las mismas, Madrid, Imprenta Nacional, 1821, Tomo VI.

Arancel general interino para gobierno de las aduanas maritimas en el comercio libre del Imperio, en Dublán, Manuel y Lozano, José María, Legislación Mexicana ó colección completa de las disposiciones legislativas expedidas desde la independencia de la República, México, Imprenta del Comercio a cargo de Dublán y Lozano, Hijos, 1876, tomo I, núm. 260.

Decreto CXIX de 14 de enero de 1812. Estincion de las matriculas de mar en las provincias ultramarinas, en Colección de los Decretos y órdenes que han espedido las Cortes generales y estraordinarias, desde su instalación, de 24 de setiembre de 1810 hasta (11 de mayo de 1814 en que fueron disueltas) Mandada publicar de órden de las mismas. Cuarta parte del Semanario Judicial,Imprenta de J.M. Lara, México, 1852-1853, Tomo I.

Decreto de 9 de noviembre de 1820 sobre Establecimiento de Depósitos, en Colección de los decretos y órdenes generales de la primera legislatura de las Cortes ordinarias de 1820 y 1821, desde 6 de julio hasta 9 de noviembre de 1820. Mandada publicar de orden de las mismas, Madrid, Imprenta Nacional, 1821, Tomo VI.

Decreto por el que se abroga la Ley de crea al Instituto Mexicano de Comercio Exterior, en el Diario Oficial de la Federación de 6 de diciembre de 1985. 
Decreto sobre comercio libre con las islas Filipinas, en Colección de los decretos y órdenes generales de la primera legislatura de las Cortes ordinarias de 1820 y 1821, desde 6 de julio hasta 9 de noviembre de 1820. Mandada publicar de orden de las mismas, Madrid, Imprenta Nacional, 1821, Tomo VI. http://infosen.senado.gob.mx/sgsp/gaceta/62/1/2012-11-27-1/ assets/documentos/INFORME_SE.pdf.

Orden Por la que se manda estender á las Américas la libertad de derechos de alcabalas y cientos en la venta de embarcaciones españolas y estranjeras, en Colección de los Decretos y órdenes que han espedido las Cortes generales y estraordinarias, desde su instalación, de 24 de setiembre de 1810 hasta (11 de mayo de 1814 en que fueron disueltas) Mandada publicar de órden de las mismas. Cuarta parte del Semanario Judicial,Imprenta de J.M. Lara, México, 18521853, Tomo I.

Real Decreto de 18 de febrero de 1789, en Pérez y López, Antonio Xavier, Teatro de la Legislación Universal de España e Indias, Madrid, en la Oficina de Don Gerónimo Ortega y Herederos de Ibarra, 1794, t.VII.

Real Decreto en que S.M. ha resuelto ampliar la concesión del comercio libre, contenida en Decreto de 16 de octubre de 1765. Instrucción de la misma fecha, y demás resolciones posteriores, que solo comprehendieron las Islas de Barlovento, y provincias de Campeche, Santa Marta, y Rio del Hacha, incluyendo ahora la de Buenos-Ayres, con internacion por ella à las demás de la America Meridional, y extension à los Puertos Habilitados en las Costas de Chile, y el Perú, Ėc. Expedido en 2 de febrero de 1778, Madrid, por Juan de San Martin, Impresor de la Secretaría de Estado y del Despacho Universal de Indias, 1778.

Reglamento y aranceles reales para el comercio libre de España y las Indias de 12 de octubre de 1778, Madrid, Imprenta de Pedro Marín, 1778. 